\title{
Análise econômica comparativa entre eletricidade e gás natural para aquecimento de água no setor residencial
}

\begin{abstract}
Até 1995, o Governo Federal detinha o monopólio das atividades de exploração, produção, refino e transporte de gás natural; e, cada estado Brasileiro exercia com exclusividade a distribuição de gás canalizado. Com a flexibilização deste cenário por meio das Emendas Constitucionais 09/95 e 05/95, respectivamente, diversas empresas passaram a atuar nas diferentes possibilidades de utilização de gases combustíveis, entre elas o aquecimento de água para banho. Apesar da utilização crescente do gás na matriz energética brasileira, a energia elétrica ainda domina uma parcela infinitamente maior do mercado de aquecimento de água no setor residencial. Todavia, os gases combustíveis constituem-se em uma alternativa ao uso de energia elétrica por ser um produto de alto valor agregado, com vantagens energéticas e ambientais. A grande quantidade de energia elétrica utilizada para banho é a principal motivação para este estudo, uma vez que se trata de uma energia muito nobre para ser utilizada para queima no processo de aquecimento de água e, aquecedores a gás, serão abordados neste estudo itens pertinentes ao deslocamento da energia elétrica para banho considerando suas eficiências durante toda a cadeia. Neste contexto, no presente trabalho, apresentase análises econômicas comparativas associadas à substituição da eletricidade pelo gás natural, ou seja, correlata à substituição tecnológica entre chuveiro elétrico e à gás para aquecimento de água no setor residencial. Outrossim, analisa-se possíveis vantagens associadas e esta substituição e energética, assim como estratégias políticas e mercadológicas para transposição de barreiras que obstaculizam esta substituição energética eminentemente tecnológica.
\end{abstract}

Palavras-chave: Aquecimento de Água; Eletricidade; Gás Natural; Eficiência Energética; Análise Econômica Comparativa.

\section{Comparative economic analysis between electricity and natural gas for water heating in the residential sector}

\begin{abstract}
Until 1995, the Federal Government had a monopoly on exploration, production, refining and transportation of natural gas; each Brazilian state exercised with exclusivity the distribution of piped gas. With the flexibilization of this scenario through Constitutional Amendments 09/95 and 05/95, respectively, several companies started to act in the different possibilities of use of combustible gases, among them the heating of water for bath. Despite the increasing use of gas in the Brazilian energy matrix, electricity still dominates an infinitely larger share of the water heating market in the residential sector. However, the combustible gases constitute an alternative to the use of electric energy because it is a product of high added value, with energetic and environmental advantages. The large amount of electric energy used for bathing is the main motivation for this study, since it is a very noble energy to be used for burning in the process of heating water and gas heaters, will be approached in this study relevant items To the displacement of electric energy to bath considering its efficiencies throughout the chain. In this context, the present work presents comparative economic analyzes associated to the substitution of electricity by natural gas, that is, the technological substitution between electric shower and gas for heating water in the residential sector. Also, possible associated advantages and this substitution and energetic, as well as political and market strategies for transposition of barriers that block this eminently technological energetic substitution are analyzed.

Keywords: Water Heating; Electricity; Natural Gas; Energy Efficiency; Comparative Economic Analysis.
\end{abstract}

Topic: Planejamento, Gestão e Políticas Públicas Ambientais

Reviewed anonymously in the process of blind peer.

\section{Danielle Johann}

Universidade de São Paulo, Brasil.

http://lattes.cnpq.br/3275064171048233

danielle@usp.br

André Felipe Simões

Universidade de São Paulo, Brasil.

http://lattes.cnpq.br/1503283535579534

afsimoes@usp.br

Erik Eduardo Rego

Escola Politécnica da Universidade de São Paulo

http://lattes.cnpq.br/6689850159735369

erikrego@usp.br
Received: 05/10/2016

Approved: 10/01/2017
Referencing this:

JOHANN, D.; SIMÕES, A. F.; REGO, E. E.. Análise econômica comparativa entre eletricidade e gás natural para aquecimento de água no setor residencial. Revista Ibero-Americana de Ciências Ambientais, v.8, n.2, p.239-249, 2017. DOI: http://doi.org/10.6008/SPC2179-6858.2017.002.0019 


\section{INTRODUÇÃO}

De acordo com previsão da Energy Information Administration (EIA, 2016) do Departamento de Energia do Governo dos Estados Unidos, a geração elétrica produzida no mundo tende a crescer a uma taxa média anual de 1,9\%, passando de 21,6 a 36,5 mil TWh, entre 2012 e 2040.

Com foco em áreas rurais, especialmente cotejando-se países em desenvolvimento, existem diversos estudos que apontam a eletrificação como forma de garantir o desenvolvimento socioeconômico em nações africanas e asiáticas) (AZIMOH et al., 2016; AKPAN, 2015; RAHMAN et al., 2013; DIOUF et al., 2013). No Brasil, como demonstram Coelho e Goldemberg (2013), o Programa Luz para Todos propiciou o acesso à eletricidade a mais de 10 milhões de brasileiros nas áreas rurais ao longo da década de 2000, garantindo-lhes condições para uma maior inclusão econômica e social. Neste contexto, frisa-se que o acesso à eletricidade no Brasil atingiu um total de $98,73 \%$ das residências que, no Brasil, encerram, em média, 3,2 moradores por domicílio, em 2010 (COELHO et al., 2013).

Nesses estudos, o acesso à eletricidade é entendido como condição essencial ao desenvolvimento. Em outras palavras, reconhece-se a tese, mais formalmente e diretamente explicitada por Costa (2009), a qual considera que o direito de acesso à energia é "meio e pré-condição" para o exercício do direito ao desenvolvimento e dos direitos humanos.

Nesses mesmos estudos, postula-se o uso da eletricidade de forma disseminada, sem a restrição aos usos finais. Coelho et al. (2013) fazem uma menção a fontes alternativas para a produção de energia elétrica, como pequenas usinas eólicas, painéis solares fotovoltaicos e PCHs (Pequenas Centrais Hidrelétricas). Os autores em foco reconhecem que estas fontes ainda têm participação insuficiente na matriz energética brasileira para serem efetivas no combate à pobreza e no incentivo à atividade econômica nas zonas de exclusão. Porém, os temas relacionados aos usos finais da eletricidade dos consumidores incluídos à rede não são abordados nesta e na quase absoluta maioria dos estudos correlatos.

Há poucos autores na literatura internacional que procuram confrontar as questões negativas associadas à tendência global de maior eletrificação dos sistemas energéticos, inclusive com expansão do uso da eletricidade em transporte e aquecimentos diversos. Nessa relativa ausência da literatura, identificase, tanto nos debates associados à promoção da eficiência energética, como nos temas endereçados à mitigação dos impactos das mudanças climáticas globais a partir da produção e uso da energia. Cabe frisar, neste contexto, que a forma como o ser humano gera e consome energia responde pela maior emissão de gases do efeito estufa antrópico quando se compara com todas as demais atividades perpetradas pelo homem (IPCC, 2013).

No Brasil, tendo em vista a predominância dos chuveiros elétricos para aquecimento de água para uso em banhos, as discussões sobre as ineficiências energéticas associadas aos usos térmicos da eletricidade deveriam estar ainda mais presentes. Os chuveiros elétricos consomem aproximadamente $6 \%$ do total da eletricidade consumida no país (EPE, 2015a). O impacto do uso dos chuveiros elétricos é ainda maior se considerado o horário de ponta (ou seja, entre 18:00h e 21:00h), afinal, os chuveiros elétricos representam 
18\% da demanda total neste intervalo (VOLPI et al., 2006); e 46,7\% da demanda de ponta do setor residencial (Racine,1998). A importância do chuveiro elétrico na curva de carga média do setor residencial é ilustrada na Figura 1, a seguir, cuja área azul clara mostra, notadamente, dois períodos de concentração de demanda.

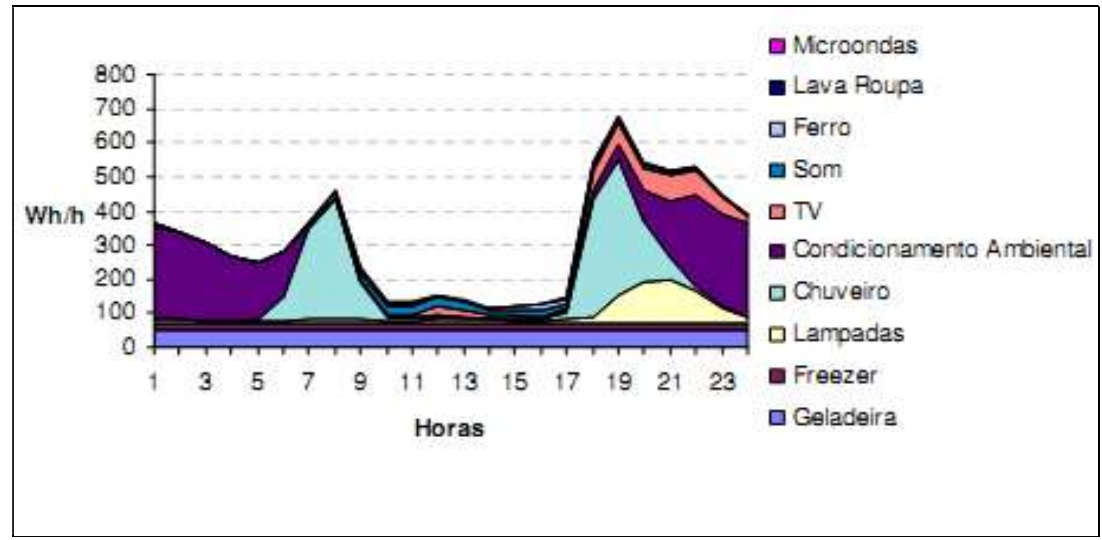

Figura 1: Curva de carga média de consumo de eletricidade residencial no Brasil. Fonte: Eletrobrás (2007).

Com base em dados inerentes a estudos capitaneados pela Eletrobrás (2007) e pela Empresa de Pesquisa Energética - EPE (2015b), plotou-se a Figura 2, a seguir, que explicita as curvas de carga por subgrupo tarifário, na qual a linha A representa os clientes de média e alta tensão (superior a 2,3kV) e, no grupo B, estão enquadrados os clientes de baixa tensão, incluindo o setor residencial, escopo deste estudo.

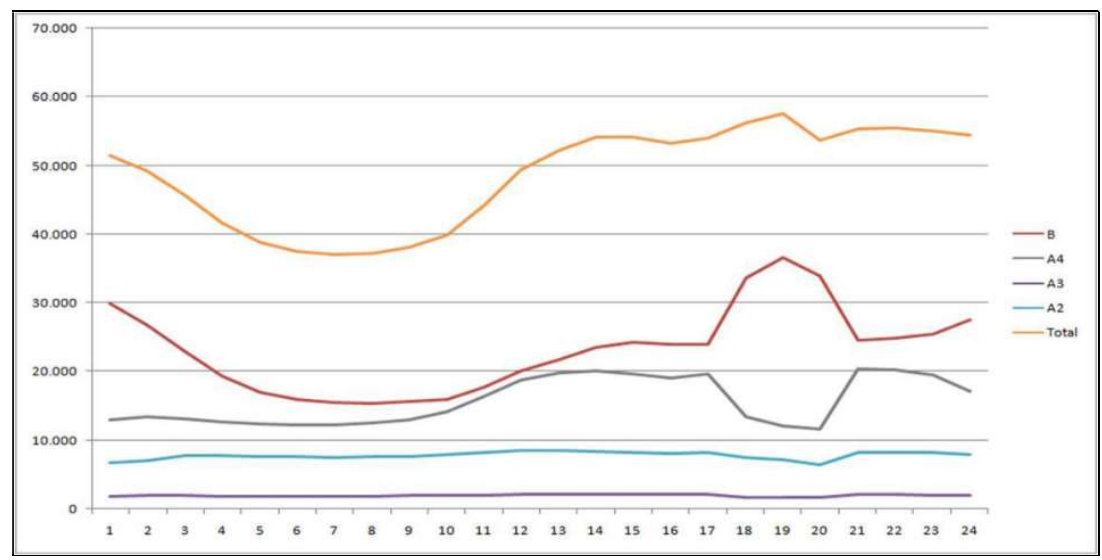

Figura 2: Curva de carga por Subgrupo Tarifário (MW). Fonte: EPE (2015b).

Analisando-se a Figura 2, constata-se que nos consumidores do grupo A, no qual o chuveiro não é um utensílio de demanda, a energia é consumida de forma mais distribuída. Já no consumidor residencial representado pelo grupo tarifário $B$, há um aumento do consumo significativo, no horário de ponta com a utilização dos chuveiros elétricos, assim como identificado na Figura 1.

Em relação a equipamentos relacionados ao aquecimento de água, dados coletados pela Pesquisa de Posse de Eletrodomésticos e Hábitos de Consumo (ELETROBRAS, 2007) indicavam que o chuveiro elétrico encontrava-se presente em $73,1 \%$ dos domicílios brasileiros e constituía a principal tecnologia utilizada para este fim $^{1}$. Aquecedores a gás, com penetração de aproximadamente $6 \%$, ocupavam um distante segundo 
lugar no ranking de tecnologias utilizadas para o aquecimento de água em domicílios. Destes, 57,6\% operavam à base de gás natural e $42,4 \%$ à base de GLP. A mesma pesquisa revelava que em aproximadamente $20 \%$ dos domicílios não se aquecia água para banho. Logo, chuveiros elétricos e aquecedores a gás eram, praticamente, as únicas tecnologias utilizadas para o aquecimento de água em domicílios quando a pesquisa foi realizada ${ }^{2}$

Levantamento elaborado pelo Instituto Brasileiro de Geografia e Estatística (IBGE) no biênio 20082009 (IBGE, 2010), no qual os entrevistados indicam qualitativamente qual ou quais fontes de energia são utilizadas para o aquecimento de água em seus domicílios, aponta para um perfil de consumo energético ainda compatível com aquele descrito no estudo da Eletrobras para o ano de 2005.

De acordo com o documento do IBGE, cerca de 75\% dos domicílios brasileiros são habitados por pessoas que aquecem água para banho. Os sistemas mais comumente observados operam com eletricidade. Esses sistemas estão presentes em aproximadamente $70 \%$ do total de domicílios, seguidos de tecnologias a gás (4\%).

A partir desse estudo é possível, igualmente, avaliar as diferenças presentes entre domicílios localizados em áreas urbanas e rurais. Conforme depreende-se da observância da Figura 3, a seguir, causa espécie a notável proporção de domicílios que não aquece água para banho em áreas rurais (quase 40\%). Também se destaca o uso da lenha (e carvão) no aquecimento de água em domicílios das zonas rurais, que supera o uso dos gases combustíveis. Da mesma forma, pode-se sugerir que o gás utilizado em aquecimento de água em domicílios de áreas rurais é, dominantemente, o GLP. Em regiões urbanas, o gás natural e o GLP dividem o espaço de atuação. Apesar dessas diferenças, a eletricidade é predominante em ambos os contextos geográficos.

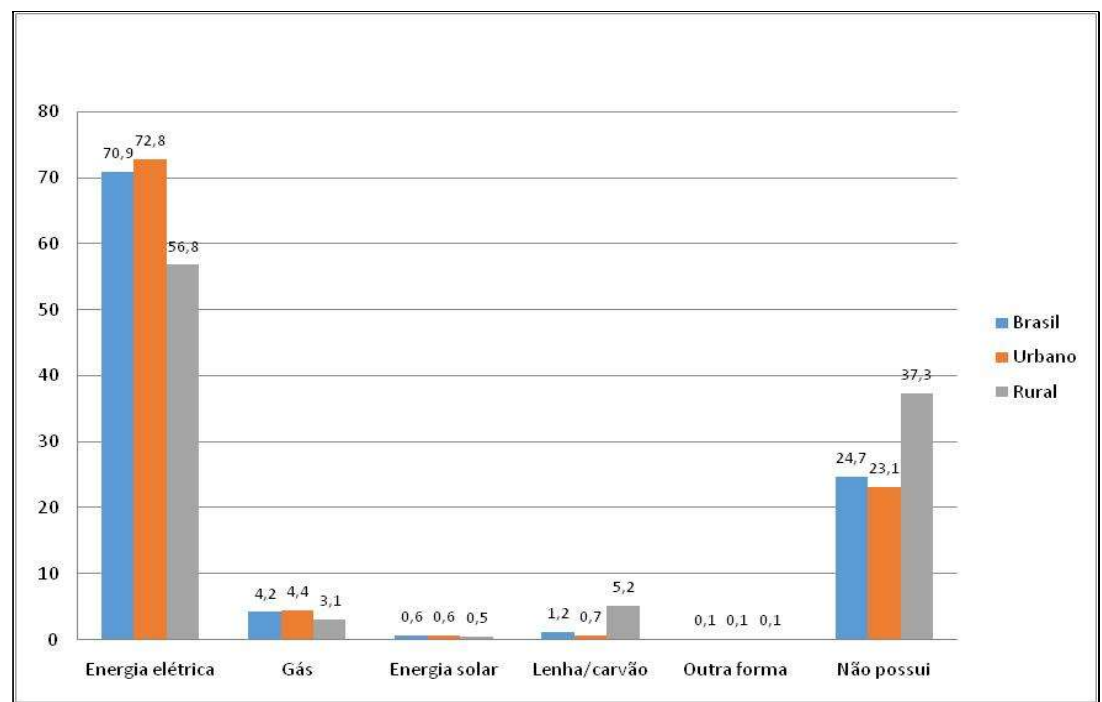

Figura 3: Percentual de domicílios por energia final utilizada para o aquecimento de água (2008-2009) Fonte: (IBGE, 2010).

massivos feitos principalmente pelo governo federal promoveram a construção de grandes projetos de geração hidrelétrica. De acordo com Martins et. al (2012) os excedentes elétricos obtidos em diferentes épocas da história energética do país justificaram a adoção de medidas de estímulo ao uso da eletricidade em muitos serviços energéticos e em todos os setores econômicos. A utilização de chuveiros elétricos para o aquecimento de água foi uma das estratégias incentivadas.

${ }^{2}$ A “Pesquisa de Posse de Equipamentos e Hábitos de Uso", elaborada pela Eletrobrás, tem o ano de 2005 como “ano-base". 
A elevada penetração de chuveiros elétricos nos domicílios brasileiros pode ser percebida no perfil de consumo elétrico residencial. Estudos focados nos usos finais elétricos deste setor indicam que o aquecimento de água é um dos processos residenciais mais relevantes em termos de consumo energético.

De acordo com os dados apresentados pela Eletrobrás (2007), chuveiros elétricos são os principais equipamentos residenciais consumidores de eletricidade e respondem, em média, por $24 \%$ do consumo elétrico do setor no Brasil (ver Figura 4). Em segundo e terceiro lugar figuram a geladeira e aparelhos de ar condicionados, responsáveis por $22 \%$ e $20 \%$, respectivamente, do consumo elétrico residencial ${ }^{3}$.

Almeida et al. (2001), apesar de apontar para um perfil de consumo elétrico ligeiramente distinto, sugerem que o aquecimento de água é, de fato, um uso final relevante em termos de demanda elétrica na medida em que ele é responsável por cerca de $20 \%$ do consumo elétrico das residenciais brasileiras, atrás apenas da refrigeração $(34,1 \%)$.

O estudo elaborado pela Eletrobrás (2007) aponta, ainda, para grandes variações inter-regionais no perfil de consumo elétrico, em especial no que diz respeito ao papel dos chuveiros elétricos. Tais diferenças são explicadas principalmente em função características climáticas locais e a consequente demanda por aquecimento de água.

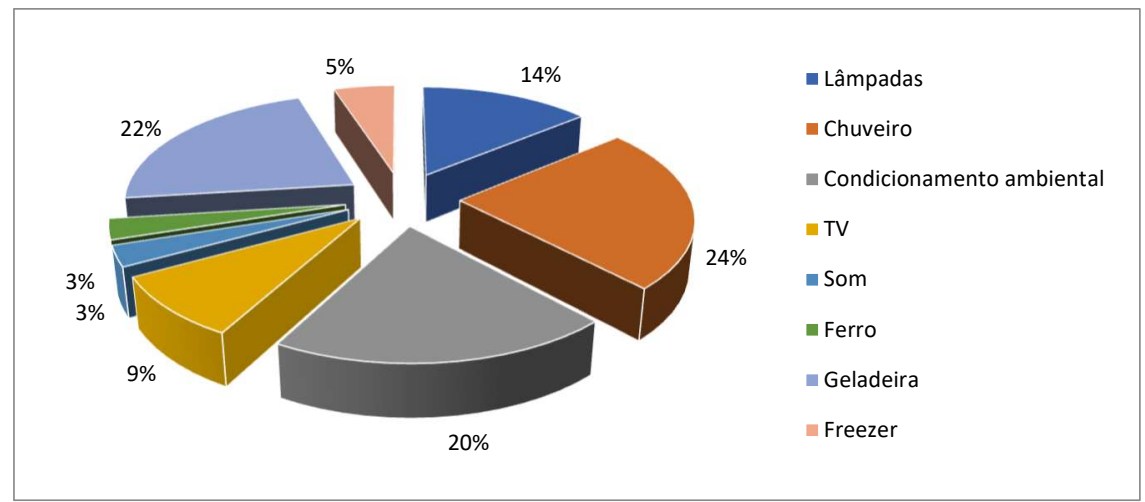

Figura 4: Usos finais dado à eletricidade no setor residencial. Fonte: Eletrobrás (2007)

Considerando os dados mais recentes sobre o consumo elétrico de chuveiros - 24\%- (ELETROBRÁS, 2007) e o consumo elétrico total pelo setor residencial - 132.049 GWh -(EPE, 2015b), observa-se que este uso final demanda $31.692 \mathrm{GWh}$ ao ano, valor equivalente a cerca de $6 \%$ de toda a eletricidade consumida no Brasil. Aplicada em chuveiros com eficiência de $95 \%$ e aquecedores de passagem a gás com eficiência de $85 \%$ (uma estimativa conservadora, de acordo com Programa Brasileiro de Etiquetagem do Instituto Nacional de Metrologia, Qualidade e Tecnologia - INMETRO), a energia útil utilizada para aquecimento residencial de água a partir de chuveiros elétricos equivale à aproximadamente $35.420 \mathrm{GWh}$.

Do ponto de vista da eficiência energética, os aquecedores a gás são mais eficientes do que os chuveiros elétricos quando se avalia toda a cadeia da geração, transmissão e distribuição de energia

\footnotetext{
${ }^{3}$ Note-se que, de acordo com esses dados, e incluindo-se a participação de freezers e ferros de passar roupas, cerca de $75 \%$ a $80 \%$ do consumo residencial de eletricidade volta-se para finalidades ditas eletrotérmicas, isto é, a energia útil realmente demandada pelos consumidores é o calor e/ou frio. Em última instância, o objetivo principal desta pesquisa é desafiar tais dominâncias tecnológicas e comportamentos culturais que sustentam demandas tão acentuadas por eletricidade para finalidades térmicas nos domicílios brasileiros. Estudos específicos necessitam ser realizados para os casos de condicionamento de ar e refrigeração. Nesta pesquisa, todas as atenções concentram-se no aquecimento de água doméstico.
} 
(JOHANN, 2015; SANTOS et al., 2013). A maior ineficiência do consumo de energia elétrica, mesmo em chuveiros elétricos, eles próprios, altamente eficientes, explica-se pelas perdas que se somam na cadeia da geração, transmissão, distribuição e uso final da eletricidade. Salienta-se que estas perdas se ampliam quando, na matriz de geração da eletricidade brasileira, aumenta a utilização de geradores termoelétricos, como tem ocorrido na matriz energética nacional.

A eficiência energética acumulada desde a produção da energia primária até o uso final é de $70 \%$ no caso dos aquecedores a gás natural, e de $35 \%$ para os aquecedores elétricos (SANTOS et al., 2011). Traduzindo essas grandezas em um Diagrama de Sankey, que compara o consumo de energia primária necessária para a produção de 100 unidades energéticas de água quente, conforme apresentado pelos autores e ilustrado na Figura 5.

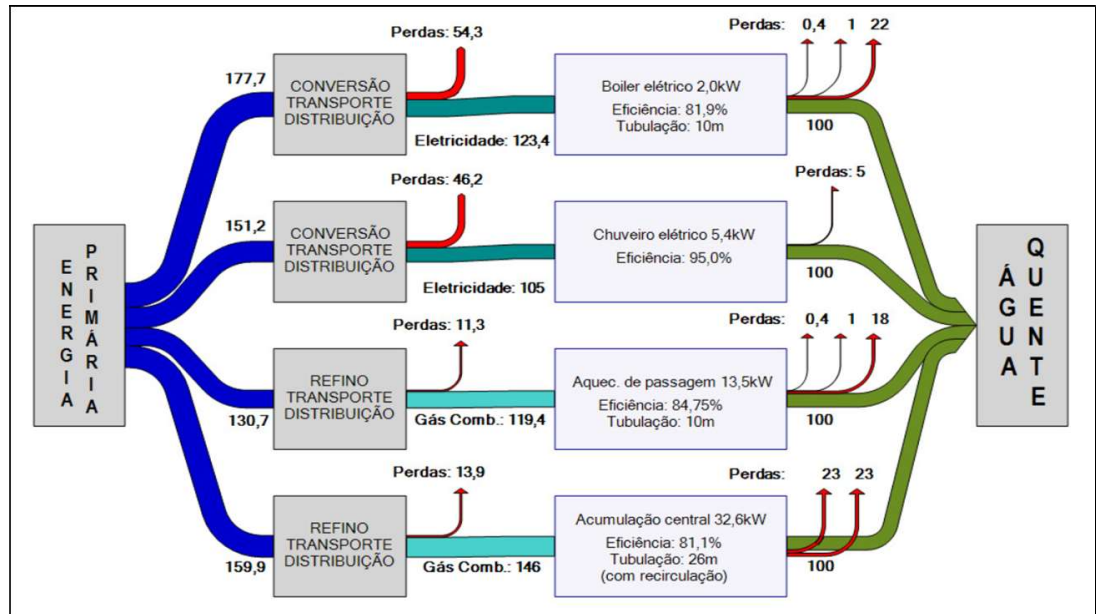

Figura 5: Análise Comparativa na Produção de Água Quente. Fonte: Santos (2011).

O diagrama explicitado na Figura 5, apresenta uma comparação de quatro sistemas para aquecimento de água: aquecedor elétrico de passagem, aquecedor elétrico de acumulação, aquecedor a gás de passagem e aquecedor a gás de acumulação. Neste esquema são consideradas as perdas em refino transporte e distribuição, as eficiências dos equipamentos, perdas no uso final. Observa-se que para a produção de 100 unidades energéticas, o sistema que demanda menor quantidade de energia primária é o aquecedor a gás de passagem (130,7 unidades energéticas), sendo, assim, a solução com maior eficiência global. Os sistemas de acumulação são menos eficientes que os sistemas de passagem, devido a necessidade de manter a água do reservatório constantemente aquecida. Nestes casos, o sistema de acumulação elétrico necessita de 177,7 unidades energéticas, e o sistema à gás natural de 159,9 unidades energéticas (Cursino dos Santos (2011)).

\section{METODOLOGIA}

Para a análise de custo de infraestrutura foi considerado apartamento com tipologia de redes de gás, elétrica e hidráulica padrão a ser descrita no decorrer do trabalho. As tarifas de água, elétrica e de gases combustíveis para a determinação dos custos de operação são das concessionárias destes insumos na cidade de São Paulo, com os parâmetros utilizados descritos, é possível replicar este estudo para outras cidades. 
Para a análise global dos custos calculados utiliza-se o Valor Presente líquido (VPL) para obter a comparação dos custos considerando os itens calculados no decorrer do artigo.

\section{Análise comparativa de custos globais de eletricidade versus gás natural para aquecimento de água}

\section{Custos de infraestrutura}

Em estudo realizado pelo SINDIGÁS (2011), foram estimados os custos de implantação das infraestruturas de rede elétrica e de aquecimento de água a gás em um apartamento padrão de 42,16 $\mathrm{m}^{2}$, incluindo dois dormitórios, sala de estar e jantar, um banheiro, área de serviço e cozinha. O projeto previu a utilização de apenas um aquecedor a gás natural, de passagem, ou de um chuveiro elétrico de $5.000 \mathrm{~W}$, exclusivamente para o banho ${ }^{4}$.

Os custos apresentados no estudo foram calculados a partir da Tabela de Composição de Preços para Orçamentos - PINI -TCPO 13. Considerando os preços divulgados pela PINI, em janeiro de 2011. Aos preços de cada material foram adicionados ainda os custos da mão-de-obra e 30\% de Benefícios e Despesas Indiretas $-\mathrm{BDI}^{5}$, para fins de cálculo do presente estudo foi feita a correção dos valores apresentados no trabalho original pelo Índice Nacional da Construção Civil de janeiro de 2011 para outubro de 2016. Os resultados são apresentados na Tabela 1.

Tabela 1: Custo da infraestrutura de gás.

\begin{tabular}{|c|r|}
\hline Custo da infraestrutura & Custo total (R\$) \\
\hline Rede básica de gás & $44.098,99$ \\
\hline Rede incremental & $70.270,11$ \\
\hline Rede hidráulica & $42.901,66$ \\
\hline Custo da implantação & $157.270,76$ \\
\hline
\end{tabular}

Fonte: Adaptado de SINDIGÁs (2011).

Na Tabela 2, são apresentados os mesmos custos para a implementação da rede elétrica necessária para a instalação de um chuveiro de $5.000 \mathrm{~W}$ de potência.

Tabela 2: Custo da infraestrutura elétrica.

\begin{tabular}{|l|r|}
\hline Custo da infraestrutura & Custo total (R\$) \\
\hline Rede básica elétrica & $78.224,41$ \\
\hline Rede incremental chuveiro de 5000 W & $156.122,01$ \\
\hline Custo da implantação & $234.346,4$ \\
\hline
\end{tabular}

Fonte: Adaptado de SINDIGÁS (2011).

A diferença entre os custos com infraestrutura necessária para as redes incrementais das duas opções de aquecimento de água é de R\$77.075,64. Esta diferença é ainda maior ao se considerar o acréscimo

\footnotetext{
${ }^{4}$ Neste estudo, para o cálculo dos custos com infraestrutura de rede para o aquecimento de água a gás, partiu-se da rede básica instalada para o fogão, foram realizados os dimensionamentos incrementais para a rede de gás visando o atendimento de aquecedores de passagem com potências entre 1.000 e $20.000 \mathrm{kcal} / \mathrm{h}$, variando a cada $1.000 \mathrm{kcal} / \mathrm{h}$. Para realização de cada dimensionamento foram quantificados os materiais necessários para a construção (ou expansão) da rede, tais como: tubos, conexões, tês e reguladores de pressão. Além da implementação da rede hidráulica, uma vez que os aquecedores a gás se encontram distantes do ponto de consumo. Para o dimensionamento e cálculo da rede elétrica foram calculadas uma rede básica e uma rede incremental para o suporte dos equipamentos com $5.000 \mathrm{~W}$ de potência.

${ }^{5} \mathrm{BDI}$ é uma taxa que se adiciona ao custo de uma obra para cobrir as despesas indiretas que tem o construtor, mais o risco do empreendimento, as despesas financeiras incorridas e os tributos incidentes na operação eventuais despesas de comercialização, o lucro do empreendedor e o seu resultado é fruto de uma operação matemática baseados em dados objetivos envolvidos em cada obra.
} 
de potência dos equipamentos. Com isto, para o caso de novos empreendimentos imobiliários, é menos dispendioso para os construtores disponibilizarem a rede de gás e a hidráulica necessária para suportar aquecedores de água a gás do que a rede elétrica necessária para suportar chuveiros elétricos com potências acima de $2.000 \mathrm{kcal} / \mathrm{h}$.

\section{Custos dos insumos}

Além dos custos com as infraestruturas, a correta análise comparativa de menor custo global deve também levar em consideração as diferenças tarifárias e do gás natural e eletricidade. Para que a energia esteja disponível para o usuário, existe a necessidade de investimento em ativos de geração, transmissão e distribuição de energia elétrica, incluindo as perdas e remuneração, que são variáveis conforme o energético a ser utilizado. Para o propósito deste estudo, adotou-se o princípio de que as tarifas de energia elétrica e gás natural devem representar e precificar esta estrutura de custos, investimentos, perdas e remuneração, dentre outros gastos, de toda a cadeia produtiva até o consumidor final. Na Tabela 3, apresentam-se os parâmetros utilizados para os cálculos dos insumos utilizados para banho nas demais tabelas.

Tabela 3: Parâmetros utilizados para cálculo de insumos.

\begin{tabular}{|c|c|c|c|}
\hline Descrições & Unidade & Chuveiro elétrico & Aquecedor a gás \\
\hline $\begin{array}{c}\text { Família (4 pessoas, } \\
1 \text { banho diário por pessoa, } 30 \text { dias) }\end{array}$ & & 4 & 4 \\
\hline Consumo de água & Litros/minuto & 3 & 7 \\
\hline Duração do banho & minutos & 10 & 11 \\
\hline Potência & $\begin{array}{l}\text { W (inverno) } \\
\text { W (verão) }\end{array}$ & $\begin{array}{l}5000 \\
3200 \\
\end{array}$ & $\begin{array}{l}\text { Pressurizador } 100 \mathrm{~W} \\
\text { Consumo de gás: } 0,90 \mathrm{~m}^{3} / \mathrm{h}(\mathrm{GN})\end{array}$ \\
\hline Custo da Água & $\mathrm{R} \$ / \mathrm{m} 3$ & 3,22 & 3,22 \\
\hline Custo do Energético & $\begin{array}{c}\mathrm{R} \$ / \mathrm{KW} \text { (elétrico) } \\
\mathrm{R} \$ / \mathrm{m} 3(\mathrm{GN})\end{array}$ & 0,59507 & $\begin{array}{c}4,741039 \\
\text { GLP: } R \$ 2,6154 / \mathrm{kg} \text { (botijão P-13) }\end{array}$ \\
\hline $\begin{array}{l}\text { Custo do Energético } \\
\text { (sem ICMS) }\end{array}$ & $\mathrm{R} \$ / \mathrm{KW}$ (elétrico) $\mathrm{R} \$ / \mathrm{m} 3(\mathrm{GN})$ & 0,44273 & 4,172114 \\
\hline
\end{tabular}

As tarifas consideradas para cálculo referem-se às concessionárias da cidade de São Paulo de água (Sabesp), gás natural (Comgás) e energia elétrica (Eletropaulo), este mesmo exercício poderia ser replicado com as tarifas destes insumos para outras cidades do Brasil. Considerou-se a perda de água no banho a gás equivalente a 1 minuto ( 7 litros) até que a água atinja a temperatura ideal para banho.

A partir dos parâmetros apresentados na Tabela 3, foram compostas as tabelas 4 e 5 , que apresentam os custos com insumos como água e gás nas bases diário e mensal. Através delas, é possível constatar que o maior consumo de água no aquecimento de água a gás influencia diretamente no maior custo total da diferença é de aproximadamente $99 \%$.

Considerando-se então os custos com investimento, conforme descrito em 3.1.1, e os custos operacionais descritos em 3.1.2, de forma a comparar o custo global (investimento e operação) dessas opções de aquecimento de água, calculou-se o valor presente líquido (VPL) de um fluxo de caixa pelo período de 20 anos, considerando-se os custos com água, gás e energia elétrica durante o horizonte de análise de 20 
anos, com os investimento iniciais explicitados nas tabelas 1 e 2 , de $\mathrm{R} \$ 234.246,40$ para o elétrico, e de $\mathrm{R} \$$ $157.270,76$ no mês zero (o custo do investimento inicial em infraestrutura).

Tabela 4: Insumos utilizados para aquecimento de água com chuveiro elétrico.

\begin{tabular}{|c|c|c|c|c|}
\hline \multirow[t]{2}{*}{ Insumos } & \multicolumn{4}{|c|}{ Chuveiro elétrico } \\
\hline & & Consumo Diário & Consumo Mensal & Gasto(R\$) \\
\hline $\begin{array}{l}\text { Água } \\
\text { (litros) }\end{array}$ & - & 120 & 3.600 & 11,59 \\
\hline \multirow{2}{*}{$\begin{array}{l}\text { Eletricidade } \\
\text { (KWh) }\end{array}$} & Verão & 2,13 & 64,00 & 38,08 \\
\hline & Inverno & 3,60 & 108,00 & 64,27 \\
\hline \multirow[t]{4}{*}{ Gás } & & - & - & - \\
\hline & & \multicolumn{2}{|c|}{ Total de gastos no verão mensais } & 49,68 \\
\hline & & \multicolumn{2}{|c|}{ Total de gastos no inverno mensais } & 75,86 \\
\hline & & \multicolumn{2}{|c|}{ Total de gastos no ano } & 753,22 \\
\hline
\end{tabular}

Tabela 5: Insumos utilizados para aquecimento de água com gás natural.

\begin{tabular}{|c|c|c|c|c|}
\hline \multirow[t]{2}{*}{ Insumos } & \multicolumn{4}{|c|}{ Aquecedor a gás } \\
\hline & & $\begin{array}{c}\text { Consumo } \\
\text { Diário }\end{array}$ & $\begin{array}{c}\text { Consumo } \\
\text { Mensal }\end{array}$ & Gasto (R\$) \\
\hline $\begin{array}{l}\text { Água } \\
\text { (Litros) }\end{array}$ & - & 308 & 9.240 & 29,75 \\
\hline $\begin{array}{c}\text { Eletricidade } \\
\text { (KWh) }\end{array}$ & Pressurização & 0,07 & 2,20 & 1,31 \\
\hline \multirow[t]{3}{*}{$\begin{array}{l}\text { Gás } \\
\left(\mathrm{m}^{3}\right)\end{array}$} & & 0,66 & 19,8 & 93,87 \\
\hline & & \multicolumn{2}{|c|}{ Total de gastos mensais } & 124,93 \\
\hline & & \multicolumn{2}{|c|}{ Total de gastos no ano } & $1.499,21$ \\
\hline
\end{tabular}

Os resultados mostram que o sistema a gás natural é menor, mesmo com o custo operacional do período maior que o elétrico: $\mathrm{R} \$ 1.500 /$ ano versus $\mathrm{R} \$ \mathrm{753} / \mathrm{ano}$, respectivamente, é mais do que compensado em função do menor custo de investimento inicial.

Nesse contexto, o VPL (taxa de desconto de 6\% a.a. real) é de $\mathrm{R} \$ 243.221$ do elétrico contra $\mathrm{R} \$$ 174.934 do sistema de aquecimento a gás natural; sendo assim, obtém-se um resultado econômico quase 40\% mais vantajoso para o aquecedor a gás, considerando-se, na íntegra, custos de infraestrutura e operação.

\section{CONCLUSÕES}

Em sistemas energéticos, a escolha da tecnologia torna-se definidora dos energéticos a serem utilizados e dos padrões de desempenho a serem alcançados. A escolha tecnológica é uma decisão ex-ante. Raramente, caberá ao usuário final alterar substancialmente o padrão tecnológico de sua edificação.

A partir das barreiras identificadas, pode-se estabelecer um conjunto de ações que permitirão o fortalecimento da adoção do aquecimento de água a gás conduzindo, consequentemente, a um uso mais eficiente da energia no setor residencial do país.

No Brasil, não existe um programa nacional (ou mesmo regional) para o incentivo do aquecimento a gás. Identificam-se programas diversos para a promoção do aquecimento de água solar, mas quase sempre sem articulação com os sistemas a gás. Existem ações em curso e outras possíveis ações que podem ser aprofundadas com o objetivo de disseminar e fomentar as atividades vinculadas ao aquecimento de água a 
gás no setor residencial. No entanto, conforme descrito neste artigo, há um desconhecimento dos consumidores brasileiros sobre os benefícios dos sistemas a gás e, portanto, o estabelecimento abrangente de políticas e estratégias tecnológicas fica comprometido.

Em locais como Estados Unidos, Canadá, Europa e Japão, bem como em países do hemisfério sul como Chile e Argentina, a dita "civilização do gás" já está disseminada e consolidada, com forte engajamento dos consumidores. Nesses ambientes, não há a menor cogitação de se promover o uso da eletricidade em substituição aos gases combustíveis nos sistemas de aquecimento de água ou calefação. Essas nações penalizam os usos inapropriados da eletricidade e explicitam suas escolhas nos programas de promoção da eficiência energética em edificações.

Este estudo comparou os custos de implementação e operação das tecnologias para aquecimento de água a gás e elétrico, e mostrou que o aquecedor a gás tem custos comparativos menores se considerados os custos com infraestrutura, a análise de eficiência entre os sistemas de aquecimento de água a partir de geração termoelétrica também aponta para uma eficiência maior do sistema de aquecimento a gás de passagem quando consideradas as perdas de toda a cadeia, desde a geração até a disposição para o usuário final.

Foram abordadas também as questões vinculadas a importância da utilização do gás para aquecimento de água como alternativa para deslocamento da energia elétrica no horário de ponta que, em uma análise mais detalhada, seria importante para garantir o fornecimento de energia elétrica neste horário (para promoção de maior de segurança energética, em especial) retirando a sobrecarga imposta pelo uso dos chuveiros elétricos de forma simultânea, o que também representaria postergação de investimentos para geração, transmissão e distribuição de energia elétrica.

E, por fim, foram calculadas as taxas de Valor Presente Líquido e devido ao investimento em infraestrutura ser muito maior no caso do aquecimento elétrico. Verificou-se, neste contexto, mesmo no cálculo para 20 anos, que o retorno do aquecedor a gás é e mais vantajoso que o aquecedor elétrico.

Neste sentido, uma correta política energética-econômica, a ser capitaneada principalmente pelo Governo Federal, seria o incentivo à instalação de sistemas de aquecimento a gás; e, para tanto, propõe-se as seguintes ações estratégicas:

Estimular a instalação de sistemas de aquecimento a gás em habitações de interesse social a exemplo do que é feito para o sistema de aquecimento de água solar, considerando a demanda de energia para aquecimento de água e o potencial de redução do consumo de energia elétrica, por meio de incentivos econômicofinanceiros, isenção fiscal para equipamentos, instalação e montagem;

Inserir o tema eficiência energética nas ações educativas do trabalho técnico social realizado junto às comunidades beneficiadas pelos programas habitacionais do Governo Federal;

Inclusão do equipamento de aquecimento de água a gás a gás junto com o financiamento do imóvel, propiciando taxas de juros menores aos consumidores. 
AGRADECIMENTOS: Ao patrocínio da Fapesp e da BG Brasil através do Reseach Centre for Gas Innovation (RCGI), FAPESP Grant Proc. 2014 / 50279-4.

\section{REFERÊNCIAS}

ALMEIDA, M.; SCHAEFFER, R.; ROVERE, E.. The potential for electricity conservation and peak load reduction in the residential sector of Brazil. Energy, v.26, p.413-429, 2001. DOI: http://doi.org/10.1016/S0360-5442(00)00071-2

AKPAN, U.. Technology options for increasing electricity access in areas with low access rate in Nigeria. Socioeconomic planning sciences, v.51, p.1-12, 2015. DOI: http://doi.org/10.1016/j.seps.2015.05.001

AVRIL, S.; MANSILLA, C.; BUSSON, C.; LEMAIRE, T.. Photovoltaic energy policy: Financial estimation and performance comparison of the public support in five representative countries. Energy Policy, v.51, p.244-258, 2012. DOI: http://doi.org/10.1016/j.enpol.2012.07.050

AZIMOH, C. L.; KLINTENBERG, P.; WALLIN, F.; KARLSSON, B.; MBOHWA, C.. Electricity for development: Mini-grid solution for rural electrification in South Africa. Energy Convertion and Management, v.110, p.268-277, 2016. DOI: http://doi.org/10.1016/i.enconman.2015.12.015

COELHO, S. T.; GOLDEMBERG, J.. Energy access: Lessons learned in Brazil and perspectives for replication in other developing countries. Energy Policy, v.61, p.1088-1096, 2013. DOI: http://doi.org/10.1016/i.enpol.2013.05.062

COSTA, M. D. A.. O direito de acesso à energia: meio e précondição para o exercício do direito ao desenvolvimento e dos direitos humanos. Tese (Doutorado em Ciências) Universidade de São Paulo, São Paulo, 2009.

DIOUF, B.; PODE, R.; OSELI, R.. Initiative for $100 \%$ rural electrification in developing countries: Case study of Senegal. Energy policy, v.59, p.926-930, 2013. DOI: http://doi.org/10.1016/i.enpol.2013.04.012

EIA. Energy Information Administration. Annual energy outlook 2016 with projections to 2040. 2016.

ELETROBRÁs. Pesquisa de posse de equipamentos e hábitos de uso: Ano-Base 2005. Rio de Janeiro: Eletrobrás, 2007.

EPE. Empresa de Pesquisa Energética. Balanço energético nacional: Ano-base 2014. Rio de Janeiro: EPE, 2015a.

EPE. Empresa de Pesquisa Energética. Nota Técnica DEA 01/15: Estimativa de Capacidade Instalada de Geração
Distribuída no SIN: Aplicações no horário de ponta. Rio de Janeiro: EPE, 2015b.

JOHANN, D.. Discussão sobre a análise de gases combustíveis para aquecimento de água no setor residencial no Brasil: uma análise SWOT. Dissertação (Mestrado em Ciências) - Universidade de São Paulo, São Paulo, 2015.

MARTINS, F. R.; ABREU, S. L.; PEREIRA, E. B.. Scenarios for Solar Thermal Energy Applications in Brazil. Energy Policy, v.48, p.640-49, 2012. DOI:

http://10.1016/j.enpol.2012.05.082

RACINE, T. A., ORESTES, M. G.. Water heating through electric shower and energy demand. Energy and Buildings, v.29, n.1, 1998. DOI: http://doi.org/10.1016/S03787788(98)00034-6

RAHMAN, M.; PAATERO, J. V.; POUDYAL, A.; LAHDELMA, R.. Driving and hindering factors for rural electrification in developing countries: Lessons from Bangladesh. Energy Policy, v.61, p.840-851, 2013. DOI: http://doi.org/10.1016/i.enpol.2013.06.100

SANTOS, A. H. C.. Eficiência energética e a contribuição dos gases combustíveis: análise de caso das políticas de avaliação de edificações. Dissertação (Mestrado em Ciências) - Universidade de São Paulo, São Paulo, 2011.

SANTOS, A. H. C. ; FAGÁ, M. T. W. ; SANTOS, E. M.. The risks of an energy efficiency policy for buildings based solely on the consumption evaluation of final energy. International Journal of Electrical Power \& Energy Systems, v.44, p.70-77, 2013. DOI: http://doi.org/10.1016/j.ijepes.2012.07.017

SANTOS, E. M.; CARRERA, G. ; FAGÁ, M. T. W. ; VILLANUEVA, L. D. Gás Natural: Estratégias para uma energia nova no Brasil. São Paulo: Annablume, 2002.

SINDIGÁS. Sindicato Nacional das Empresas Distribuidoras de Gás Liquefeito de Petróleo. Estudo Comparativo da Infraestrutura e uso do Energético (Eletricidade \& Gás LP) para Aquecimento de Água em uma Edificação Residencial. SINDIGÁS, 2011.

VOLPI, G.; JANNUZZI, G. M.; GOMES, R. D. M.. A sustainable electricity blueprint for Brazil. Energy for Sustainable Development, v.10, n.4, p.14-24, 2006. DOI: http://doi.org/10.1016/S0973-0826(08)60552-9 